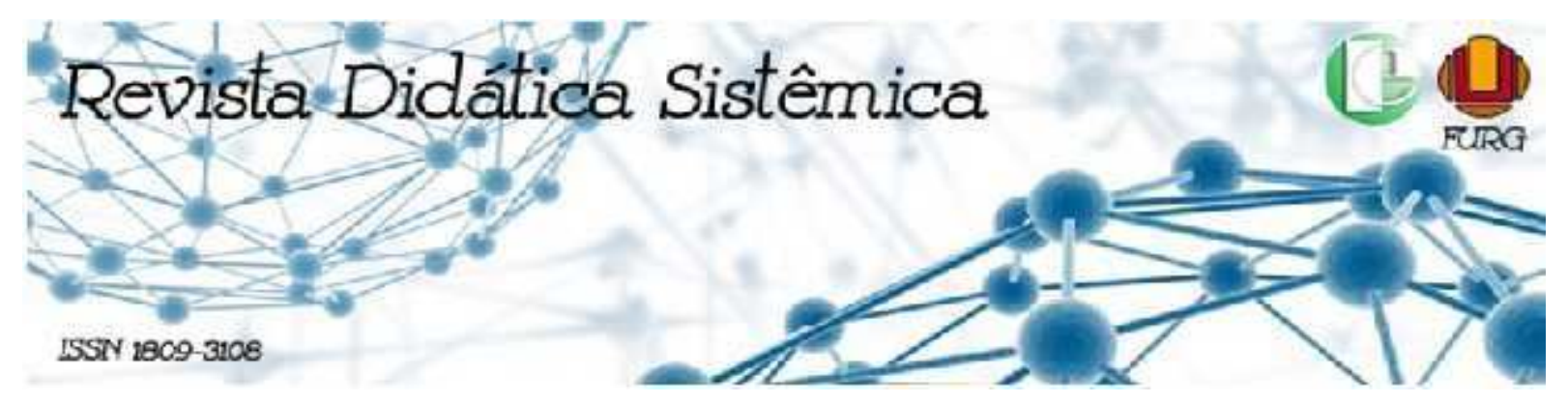

\title{
MÚLTIPLAS LINGUAGENS NAS/DAS (COM/PARA AS) INFÂNCIAS: AS REPRESENTAÇÕES DAS CRIANÇAS
}

\author{
Eliane Lima Piske ${ }^{1}$ \\ Pamela Saraiva Miranda ${ }^{2}$ \\ Narjara Mendes Garcia ${ }^{3}$ \\ Maria Angela Mattar Yunes ${ }^{4}$
}

\section{RESUMO}

O artigo entrelaça as infâncias, nas escolas de turno integral, pela perspectiva da Educação Ambiental Sistêmica, com o objetivo de identificar as representações, uma das múltiplas linguagens expressas pelas crianças que possibilitaram outras tantas linguagens, tendo como mediadores desse processo as educadoras das infâncias. Ancoramos o estudo pela base teórico-metodológico da Bioecologia do Desenvolvimento Humano com a Inserção Ecológica. Para a análise dos dados, utilizamos a Teoria Fundamentada nos Dados, zelando pelos processos e pelas etapas da investigação, identificando que os desejos das crianças e das educadoras das infâncias evidenciam a necessidade de uma construção coletiva, sendo necessário o deslocamento das práticas rotineiras para o desenvolvimento de práticas educativas ambientais nos momentos das rotinas.

Palavras-chave: infâncias. Educadores. Educação Ambiental Sistêmica. Múltiplas linguagens.

\section{MULTIPLE LANGUAGES IN/FROM (WITH/TO) CHILDHOODS: CHILDREN'S REPRESENTATIONS}

\begin{abstract}
The article interweaves childhoods in full-time schools from the perspective of Systemic Environmental Education with the aim of identifying representations, one of the multiple languages expressed by children and that enabled many other languages, with childhood's educators as mediators of this process. We anchored the study on the theoretical and methodological basis of the Bioecology of Human Development with Ecological Insertion. For the data analysis we use the Grounded Theory, looking

\footnotetext{
${ }^{1}$ Doutora em Educação Ambiental pelo Programa de Pós-Graduação em Educação Ambiental na Universidade Federal do Rio Grande (PPGEA/FURG). Colaboradora no Centro de Referência em Apoio às Famílias (CRAF/FURG). Integrante do Grupo de Estudos Ecoinfâncias. Professora da rede pública no município de Rio Grande, RS. E-mail: e.nanny@hotmail.com

2 Mestre em Educação Ambiental pelo Programa de Pós-Graduação em Educação Ambiental na Universidade Federal do Rio Grande (PPGEA/FURG). Professora da rede pública no município de Rio Grande, RS. E-mail: ms.pamelasaraiva@gmail.com

${ }^{3}$ Doutora em Educação Ambiental pelo Programa de Pós-Graduação em Educação Ambiental (PPGEA/FURG). Professora do Instituto de Educação da Universidade Federal do Rio Grande (IE/FURG). E-mail: narjaramg@gmail.com

${ }^{4}$ Doutora em Educação pela Pontifícia Universidade Católica de São Paulo (PUC-SP). Professora do Programa de Pós-Graduação em Psicologia, UNIVERSO, Niterói, RJ. E-mail: mamyunes@yahoo.com
} 
after the processes and stages of the investigation, identifying that the wishes of children and childhood's educators highlight the need for a collective construction, requiring the displacement of routine practices for development of environmental educational practices at the time of routine.

Keywords: childhoods. Educators. Systemic Environmental Education. Multiple languages.

\section{INTRODUÇÃO}

As interconexões bioecológicas da Educação Ambiental Sistêmica, mobilizada pelas múltiplas linguagens nas/das (com/para as) infâncias, a partir das representações das crianças na Educação Infantil e dos Anos Iniciais, foram o cerne do artigo. A presente proposta teve como objetivo identificar as representações, uma das múltiplas linguagens expressas pelas crianças que possibilitaram outras tantas linguagens, tendo como mediadores desse processo as educadoras das infâncias.

O texto foi criado pela oportunidade de investigar perspectivas ancoradas nas múltiplas linguagens na Educação Infantil (EI) e dos Anos Iniciais (AI). A EI é a primeira etapa da Educação Básica e tem por finalidade o desenvolvimento integral das crianças até seis anos de idade, conforme estabelece a Lei de Diretrizes e Bases- LDB (BRASIL, 1996). Dos Anos Iniciais, compreendem do $1^{\mathrm{a}}$. ao $5^{\mathrm{a}}$ ano do Ensino Fundamental (BRASIL, 1996). Para apresentar o entrelace teórico-metodológico da investigação, destacamos que isso somente foi possível pelo encontro de interesse de duas educadoras ambientais das infâncias que realizam suas pesquisas de Mestrado e de Doutorado pelo Programa de Pós-Graduação em Educação Ambiental pela Universidade Federal do Rio Grande- PPGEA/FURG.

A base teórica da Bioecologia do Desenvolvimento Humano- TBDH, de Urie Bronfenbrenner (2011), com o fundamento metodológico pela Inserção Ecológica (CECCONELLO e KOLLER, 2004; PISKE, et al., 2018), designou as contribuições para as intervenções com as crianças e as educadoras de duas escolas de turno integral. As representações das crianças foram registradas através de desenhos e de fotografias e das anotações naturalísticas realizadas em diários de campo. Para a análise das informações, utilizamos a Teoria Fundamentada nos Dados- TFD CHARMAZ, 2005; (CASSIANE, CALARI e PELÁ, 1996; PISKE, et. al., 2018).

Apresentar o panorama sistêmico dos processos de socialização das crianças pelas múltiplas linguagens possibilitou compreender que esses atores sociais se percebem pertencentes à natureza, em situações complexas e em inter-relação com outros seres naturais e 
integram os ambientes em sua totalidade. Assim, apresenta-se o subitem a seguir:

\section{PANORAMA SISTÊMICO DOS PROCESSOS DE SOCIALIZAÇÃO DAS CRIANÇAS PELAS MÚLTIPLAS LINGUAGENS NAS ESCOLAS DE TURNO INTEGRAL}

Apresentamos a necessidade de entrelaçar os processos de socialização das crianças pelas múltiplas linguagens possíveis nas escolas de turno integral. Muitas vezes, o engessamento da visão sobre o cotidiano das escolas de tempo integral não facilitam enxergar para além do que é exposto. Assim, não se deve naturalizar um olhar que deveria ser sensível para as práticas educativas nas escolas de tempo integral.

As educadoras das infâncias devem e precisam estar sempre em um processo contínuo de implicação e deslocamento diante do cotidiano dos contextos de tempo integral, como anuncia Boff:

Tanto o "implicar" quanto o "deslocar" significa movimento. Mas o educador não faz o seu trabalho anunciando que vai promover o movimento das pessoas. Ao invés de anunciar qualquer promessa de mudança ou de alguma mágica, é preciso organizar as vivências. Esta organização depende de um ambiente suficientemente bom para convidar cada participante a se lançar no movimento e na experimentação dos novos modos de estar na vida. Isto não se faz por meio de decretos. É preciso preparar ambientes convidativos e sustentar os pequenos movimentos, os gestos mais tímidos, que surgem na medida em que as pessoas se sentem confiantes. $\mathrm{O}$ educador precisa desta habilidade para superar o trabalho da conscientização e insistir no trabalho das vivências. (BOFF, 2012, p. 40).

Neste sentido, as ações de "implicar" e "deslocar" precisam ser um convite para as crianças ao contemplar as múltiplas linguagens, em que os educadores das infâncias devem assumir o papel de mediadores nas atuações, conforme destaca Tubenchlak:

como vimos, o papel do professor passa por um processo de descentralização: de foco principal nos ambientes educativos, transforma-se em alguém que habita também os bastidores, que cria previamente seus planejamentos amalgamados às escolhas espaciais e materiais (TUBENCHLAK, 2020, p. 39).

Vale mencionar que as vivências devem ser experienciadas por todos que estão imersos no processo educativo. A interlocução entre turno integral e as múltiplas linguagens necessitam ser fortalecidas com as crianças, diante das práticas educativas ambientais, com o intuito de romper com a visão reducionista, que relaciona e limita a atuação das crianças em hortas e/ou separação de materiais recicláveis, bem como propõe discussões superficiais sobre a 
preservação do meio ambiente. Contudo, é preciso reconhecer que essas ações, também, são de extrema importância e necessárias, mas os temas ambientais pelas múltiplas linguagens não podem se condensar somente nisso. É importante extrapolar os horizontes e incluir as crianças como protagonistas na construção de seu próprio viver, pois as crianças são agentes influentes e influenciadores na vida dos demais organismos e das dimensões coletivas (CAPRA, 2006).

As práticas educativas ambientais contribuem para a construção integral do "ser" e para o sentimento de pertencimento ao "estar" no e com o mundo (PISKE, MADRUGA e GARCIA, 2018). Entendemos que esta construção integral da criança é permeada e desenvolvida pela e com a temporalidade, momento que surge um importante questionamento: como as escolas, enquanto instituição social, que recebe e acolhe as crianças, estão se organizando na questão do tempo?

Refletir sobre como o tempo está sendo concebido, organizado e proporcionado às crianças é fundamental, pois compreendemos que este não é um fenômeno que faz parte do viver das infâncias nos contextos. Oliveira e Marques (2011, p. 174) destacam que "todos temos memórias das marcas temporais vividas no cotidiano da escola", lembranças que surgem como flash, resgatando os sentimentos, as sensações e trazem à memória os espaços que pareciam ser maiores do que realmente são, o cheiro que vinha da cozinha em momentos das refeições, a cama como elemento de parada obrigatória de um corpo que, muitas vezes, ainda queria mais movimentação. Direções que significavam as experiências temporais vivenciadas nas rotinas e que se instauram no cotidiano.

Temporalidade que proporciona momentos de encontros e desencontros diante das rotinas que acabam, muitas vezes, "engolindo" o cotidiano. O cotidiano das escolas de turno integral, segundo Oliveira e Marques (2011, p.175), se constitui num tempo em que "podemos encontrar as contações de histórias, o teatro, as gincanas, os conteúdos experienciados em projetos, sem a organização rígida do sino, da seriação, da fragmentação do saber". e as rotinas são como parte integrante deste tempo diário.Conforme Oliveira e Marques (2011, p. 175), "podem ser consideradas como ações culturais produzidas e reproduzidas no cotidiano com a finalidade de organizar a cotidianidade".

Cotidiano e rotina não são sinônimos. As rotinas são organizações que se estabelecem e se desenvolvem dentro do cotidiano. O tempo diário das crianças dentro das escolas, de turno integral, iniciam com a chegada das mesmas no contexto e tem seu término ao final do dia, com a despedida e o retorno para os lares. Diante disso, surge uma inquietação: o que acontece entre o início e o término do período é um percurso percorrido pelo processo sequencial ou vivencial? 
De acordo com Vasconcellos (2009), a criança rompe a lógica sequencial do tempo determinado, seja do cotidiano, seja das rotinas, mesmo quando este é imposto:

[...] encontram rotas de fugas. Brechas para um tempo de pausa. Para a vivência amorosa e preguiçosa do prazer de descobrir a si e ao mundo. Não é um tempo de ação. É um tempo de atenção. Mas não a atenção difusa, aberta, à espera ou à espreita não se sabe bem de quê. É uma atenção ao que está fora, mas também ao que está dentro. [...] E, nesse sentido, contemplar é também contemplar-se (VASCONCELLOS, 2009, p. 90).

Nessa perspectiva, a compreensão sobre um processo educativo integral não pode ser pautada na proposição de atividades sequenciais diversificadas que reforçam o encerramento do ser em seu próprio corpo e a construção da categoria aluno (KAPLAN e SARAT, 2017). Compreender que, "ao se pensar a formação integral das crianças, é necessário possibilitar espaços e tempos educativos que sejam dialógicos e reflexivos”, (Carvalho,2015, p. 39) cria oportunidades por meio das práticas educativas ambientais para o desenvolvimento das crianças em todas as dimensões e contribui, fundamentalmente, para a formação humana.

É fundamental que o espaço escolar se torne um território de movimento pelas múltiplas linguagens das/pelas (para/com as) infâncias, momento que é possível vivenciar pelas várias maneiras para se sentir pertencente ao contexto coletivo. Contemplaras especificidades que ali emergem, ou seja, infâncias e contextos estão relacionados e ambos estão conectados com o tempo disponibilizado para as vivências infantis do cotidiano é igualmente importante. Portanto, é necessário deixar de ser um território de (des)encontros diante das limitações do cotidiano ao caminhar para possibilitar o encontro das múltiplas linguagens nas escolas de tempo integral.

Reforçamos a força das díades ou N+3, na educação das crianças, ao contemplar as múltiplas linguagens para apresentar a estratégia metodológica na perspectiva sistêmica ambiental denominada Inserção Ecológica. Conforme pode ser acompanhada com o subitem a seguir, foi a metodologia usada nas escolas de tempo integral:

\section{BIOECOLOGIA DO DESENVOLVIMENTO HUMANO E INSERÇÃO ECOLÓGICA: EMBASAMENTO TEÓRICO-METODOLÓGICO}

O encontro das duas educadoras ambientais das infâncias, no Programa, foi a possibilidade para escrever o artigo, já que as discussões foram (são) fortalecidas no Grupo de 
Estudos Ecoinfâncias (PISKE, NEUWALD e GARCIA, 2018). As perspectivas sistêmicas das dimensões bioecológicas foram a mola propulsora das junções da Bioecologia do Desenvolvimento Humano (BRONFENBRENNER, 2011) com a Educação Ambiental Sistêmica, pela base metodológica, pela Inserção Ecológica.

A compreensão de que as crianças são atores sociais, num modelo teórico de processopessoa-contexto-tempo (PPCT), é um aspecto que nos possibilita vincular com a teoria Bioecológica do Desenvolvimento Humano (BRONFENBRENNER, 2011) e o embasamento metodológico da Inserção Ecológica em uma Escola de Ensino Fundamental de Tempo Integral e outra Escola de Educação Infantil de tempo integral. Ambas estão no extremo Sul do Rio Grande do Sul, sendo uma delas no município de Rio Grande (RG) e a outra no Chuí. O município do Chuí é uma cidade fronteiriça entre Brasil e Uruguai. A Escola de Ensino Fundamental de Tempo Integral será identificada pelas iniciais EEF-RG, e a Escola de Educação Infantil será identificada pelas iniciais com o nome EEI-Chuí.

Ambas as escolas são de turno integral da Educação Básica, com jornada de duração igual ou superior a sete horas diárias (BRASIL, 2010). As rotinas são organizadas em momentos, tais como: hora da roda, hora da atividade, hora do pátio e/ou praça, hora do almoço, hora da higiene, hora do descanso, dentre outras períodos que compreendem a rotina diária das crianças nas escolas de turno integral.

Participaram da pesquisa 38 crianças, da EEF-RG, com as idades entre 7 até 9anos e 12 educadoras das infâncias. Na EEI-Chuí, participaram 20crianças na faixa- etária de 3 até 4 anos e 02 educadoras das infâncias. Neste momento, salientamos que infâncias, crianças e educadoras ambientais das infâncias não são sinônimos. As infâncias foram construídas ao longo da época e são sempre os modos como a sociedade e os educadores percebem e compreendem os costumes. Já as crianças são atores eco-psico-bio-historico-sociais, que, de acordo com o Estatuto da Criança e do Adolescente- ECA (BRASIL, 1990),compõe a faixaetária de cidadãos de zero até doze anos incompletos. E os educadores ambientais das infâncias são as professoras.

Na perspectiva do Modelo PPCT, o processo é a interação recíproca entre as pessoas, o contexto e o tempo. Bronfenbrenner (2011), em seus estudos, não chegou a estruturar uma metodologia que compreendesse o PPCT na totalidade de sua teoria. Nesse sentido, utilizamos a Inserção Ecológica (CECCONELLO e KOLLER, 2004; PISKE, et al., 2018) que possibilita perceber o desenvolvimento humano a partir dos quatro elementos apresentados na Teoria Bioecológica do Desenvolvimento Humano. As representações das crianças foram registradas 
através de desenhos e das fotografias, além de contar com o registro, nos diários de campo, das observações naturalísticas realizadas durante as inserções na EEF- RG, em dias e horários alternados e na EEI- Chuí.

Para a análise das informações, utilizamos a Teoria Fundamentada nos Dados (CHARMAZ, 2005; CASSIANE, CALARI e PELÁ, 1996; PISKE, et. al., 2018). Os procedimentos para a análise das informações produzidas convergiram para a sistematização dos mesmos, dividindo-os, elencando-os por categorias, conceituando-os e criando uma relação entre si. Os princípios éticos foram essenciais para o desenvolvimento da pesquisa, e os educadores das infâncias tiveram que autorizar a divulgação das informações, através de Termos de Consentimentos Livres e Esclarecidos (TCLE), assim como foi assinado o Termo de Assentimento (TA) (MISSIO; ARPINI, 2018) pelas crianças que puderam se manifestar por meio dos desenhos.

\section{CONTEXTUALIZAR AS MÚLTIPLAS LINGUAGENS COM AS CRIANÇAS: EVIDÊNCIAS POSSÍVEIS PELA EDUCAÇÃO AMBIENTAL SISTÊMICA}

Os processos proximais são entendidos enquanto formas particulares de interação entre os sujeitos e destes com o ambiente, que, ao longo do tempo, se organizam de formas progressivamente mais complexas. Esses processos tanto podem ser conduzidos por relações interpessoais, bem como pela interação da pessoa em desenvolvimento com os objetos e os símbolos, sem a presença de outras pessoas. Mas, neste artigo, nosso olhar é para as interações entre os educadores $\mathrm{e}$ as crianças que se constituem em processos proximais (BRONFENBRENNER, 2011) nos diferentes contextos educativos.

O ambiente é composto por contextos ecológicos, desde os mais proximais até os mais distantes, situados no lugar e no tempo histórico. A representação dos níveis ambientais pode ser observada a partir do desenho de João. As percepções dele remetem ao PPCT e, ao representar o contexto escola, as pessoas, o processo e o tempo estão em interação e sofrem influências. João deixa evidente seu descontentamento pelas fragilidades registradas num dos desenhos: de um lado da folha, ele delineou uma escola; do outro lado do papel, a escola que ele gostaria de experienciar, conforme João disse: "a mãe tava aqui e eu desenhei a escola que eu chego de "bus" e a escola que seria a melhor, muito boa" (diário de campo, set. 2018). Apresentamos, a seguir, as duas imagens: 
Imagem 1 - escola de tempo integral

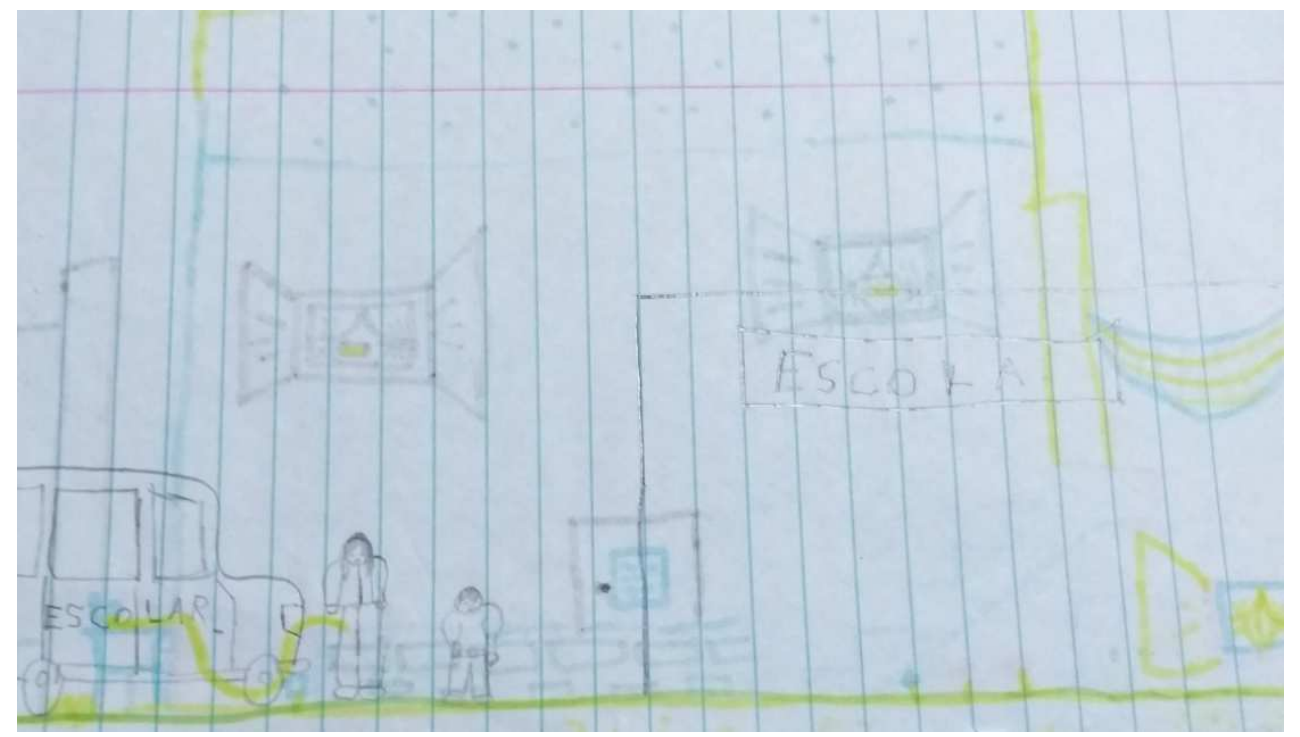

Fonte: João, 8 anos.

Imagem 2 - perspectiva daescola de tempo integral

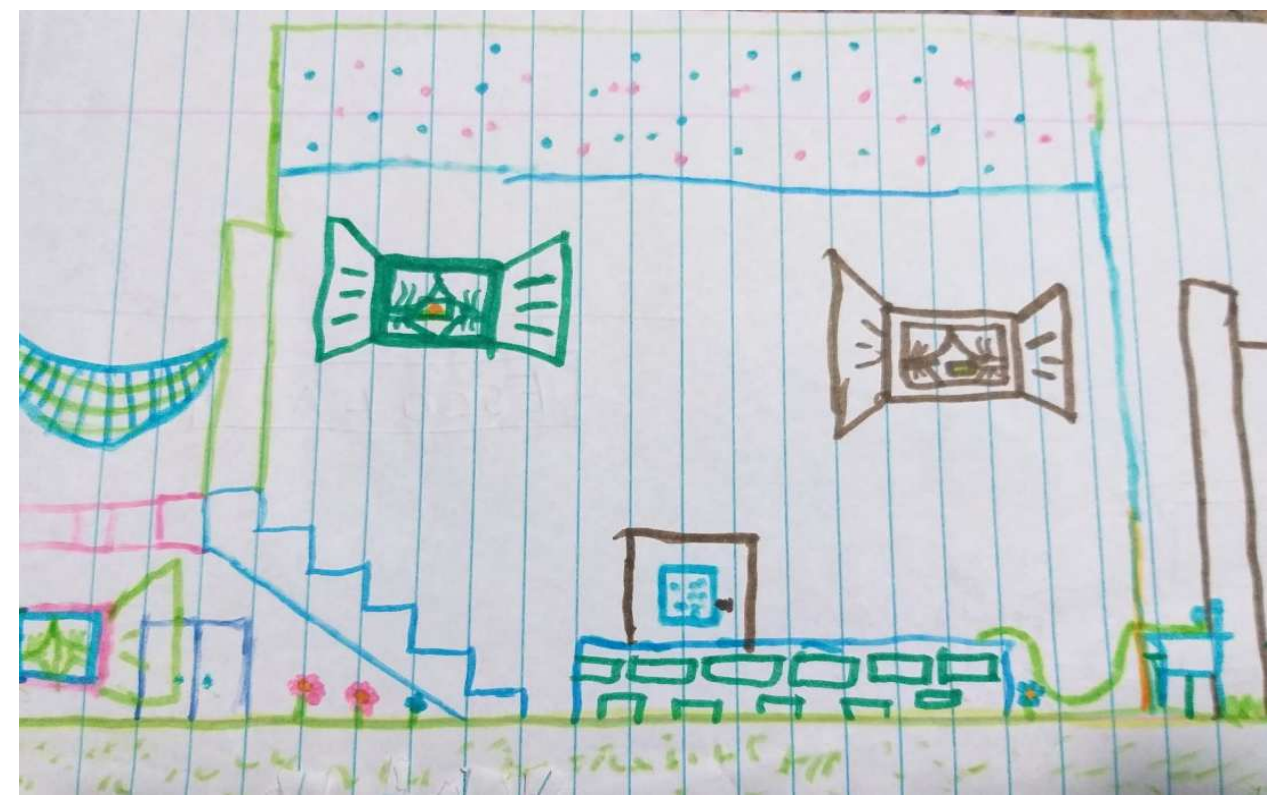

Fonte: João, 8 anos.

Nesse sentido, o modelo explicativo do desenvolvimento humano deve ser composto e compreendido na ótica das quatro dimensões inter-relacionadas: processo, pessoa, contexto e tempo (PPCT). Casualmente, João desenhou a escola com olhos humanos, dentro das janelas da escola de tempo integral, ao remeter o cuidado com o contexto-pessoa e destacar os quatro elementos, água, terra, fogo e ar, os quais podem ser acompanhados pela imaginação do João ao contornar a figura 2. Além do PPCT, está presente a água, a terra, o ar e o fogo. 
A visão sistêmica é uma forma de olhar o mundo, e a teoria Bioecológica do Desenvolvimento Humano (BRONFENBRENNER, 2011) é mais que uma abordagem para as práticas educativas ambientais. A teoria é uma forma de perceber as pessoas e integrar ao relacionar o olhar para as relações, que é sistêmico! (PISKE, GARCIA e YUNES, 2019). Obviamente, não podemos apresentar somente as percepções das crianças, precisamos atentar, também, para o que desejam as educadoras sobre as mudanças que gostariam que tivessem.

Entendemos que, para implicar-se com os processos desenvolvidos, foi preciso um movimento de desacomodação, inquietação e reflexão, um constante (re)significar das concepções e das práticas rotineiras. Dessa maneira, evidenciamos o borbulhar de desejos que anseiam por mudanças a partir da percepção das educadoras:

[...] eu desejo essa escola diferente do que ela é hoje, o discurso é tão bonito sobre promover tudo com a participação das crianças, mas quando nos deparamos com tudo o que temos que fazer me pergunto o que de fato construímos coletivamente? apenas projetos em sala?. Fico pensando se é só nós quem vivemos assim, nessa correria do dia a dia e se for, porque não mudamos? se a problemática se encontrar em mim, eu estou disposta a mudar! (Diário de campo. Educadora B. mar. 2019).

Nós queríamos que muitas coisas aqui mudassem! Sempre desejamos uma escola que respeite as crianças, acolha e incentive nas investigações sobre tudo e não somente nas indagações que estão relacionadas ao projeto. É preciso estudo, discussão sobre nossas inquietações, diálogos construídos no coletivo e uma formação pedagógica consistente para romper com a visão estabelecida e práticas desenvolvidas sobretudo nas rotinas. Não quero apenas ficar sonhando com o que pode ser feito na escola com as crianças, eu quero ação, eu quero praticar mesmo que eu venha a errar, eu quero sobretudo tentar todas as mudanças possíveis de serem realizadas (Diário de campo. Educadora A. mar. 2019).

Neste panorama, identificamos que os desejos das pessoas por mudanças estão alicerçados em uma perspectiva que busca a construção coletiva dos processos e do contextotempo. Salientamos que é necessário o deslocamento das práticas rotineiras para o desenvolvimento de práticas educativas ambientais nos momentos das rotinas. Na medida em que se ampliam, fortalecem o repertório de conceitos que são (re)significados na prática com as crianças, por meio das vivências experienciadas pelas múltiplas linguagens.

As interconexões apresentadas subsidiaram as relações bioecológicas das múltiplas linguagens para o desenvolvimento humano nas infâncias. Talvez, por ora, possa parecer estranho concluir uma investigação trazendo uma imagem que inquieta, mas não finda o entrelace da Educação Ambiental Sistêmica nas escolas de tempo integral. Nesse ínterim, a imagem justifica e fortalece as múltiplas linguagens vivenciadas pelas bases teóricas e 
metodológicas resultantes das informações que emergiram, conforme podemos visualizar com a figura a seguir:

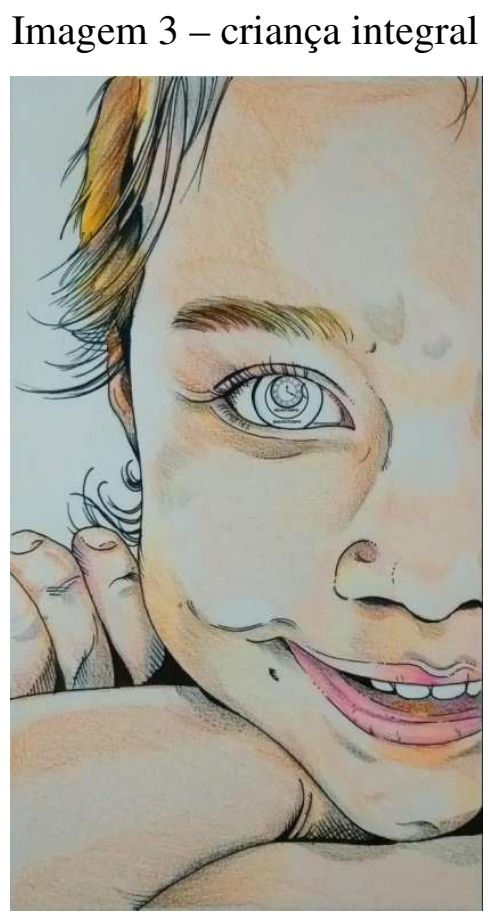

Fonte: produzido pelo artista Bruno Rodrigo Souza dos Santos, maio, 2020.

A imagem é uma produção baseada em um registro fotográfico realizado durante o processo de investigação na EEI- Chuí, figura que sensibiliza o ser criança integral. Em nenhum momento, fizemos uma análise dos desenhos nem das fotografias. Salientamos a importância da Inserção Ecológica das pesquisadoras para compreender os elementos PPCT para o desenvolvimento humano nas/das (para/com as) infâncias.

Entendemos que as práticas educativas ambientais começaram a surgir no contexto ecológico da pesquisa, com e por meio dos movimentos, sendo processos baseados nas concepções de educação integral, que rompem com a sequencialidade do tempo e do ambiente ao compreender a criança como ser integral, com peculiaridades e com múltiplas linguagens, sendo uma delas explorada ao longo do artigo, as representações por meio da arte.

\section{PONTOS QUE INQUIETAM E DEIXAM MARCAS TEMPORAIS}

Chegar ao final, não necessariamente, significa concluir as investigações com as crianças e com as educadoras ambientais das infâncias nas escolas de tempo integral. Fora 
elencados os indícios que reforçaram a necessidade de as pesquisas serem construídas e fortalecidas com os atores sociais que possibilitaram contextualizar a bioecologia das infâncias com a Educação Ambiental Sistêmica.

Ressaltamos que compreender a criança, em sua inteireza, implica não fragmentar os modos de ser e de viver ao experienciar os tempos (Macrotempo, Mesotempo e Microtempo). As informações analisadas ressaltam que as crianças tiveram a oportunidade de se desenvolver sistemicamente e simultaneamente na e com a temporalidade das escolas de tempo integral. Identificamos que o olhar bioecológico das crianças e das educadoras das infâncias evidenciaram as fissuras existentes nos processos e no tempo experienciados, dando indícios de possibilidades para serem (re)significadas com e por meio das concepções da Educação Ambiental Sistêmica.

O olhar que contempla a criança como ser integral, ao relacionar as concepções de Chronos e Kairós com as dimensões temporais do cronossistema, nos contextos microssistêmicos, está representado pela imagem acima. Entendemos que ouvir as crianças, em seus tempos, foi uma possibilidade para compreender a criança inteira e sistemicamente na e com a temporalidade das escolas de tempo integral.

A partir de um olhar bioecológico, as crianças e as educadoras demonstram compreender o tempo cronológico. Destacamos quando salientam ser extenso o tempo de permanência na escola, as sequencialidades das rotinas, a (de)marcação do tempo no relógio, principalmente, por meio da fala das educadoras ao destacar os períodos. Vale mencionar que as crianças entendem a temporalidade subjetiva pelos exemplos: ao distinguir ser pouco ou muito tempo e, também, ao relacionar os fenômenos da natureza (dia e noite) com o tempo de permanência na escola.

Sublinhamos, ainda, que evidências enunciadas pelas crianças reforçam uma concepção de tempo subjetiva: o tempo da criança. A temporalidade precisa ser respeitada nos contextos microssistêmicos, pois o contexto-tempo é experienciado com as crianças por meio do viver os processos e não por cronometrar os períodos. Nesse sentido, é que as relações entre o tempo da criança, como ser humano integral no contexto, se fortalecem com os pressupostos da Educação Ambiental Sistêmica nas escolas de tempo integral, proposições que promovem qualidade de vida. Nessa perspectiva é que compreendemos a dimensão temporal das crianças nas escolas de tempo integral como um processo da Educação Ambiental Sistêmica. Identificamos as repercussões no microtempo das infâncias, ao possibilitar tempos de encontros para a produção cultural do brincar, da interação e da socialização infantil, bem como nas práticas pedagógicas 
que se deslocaram das práticas rotineiras para práticas educativas ambientais.

Os elementos apresentados, no artigo, estão (são) interconectados pelas múltiplas linguagens nas/das (para/com as) infâncias, e o movimento do registro apresenta a indissociabilidade dos rudimentos bioecológicos, que ora vai e, em outros, retorna, o que justifica que as informações sejam entrelaçadas pelas dimensões de processo-pessoa-contextotempo para o desenvolvimento humano nas/das (para/com as) infâncias.

Agradecimento à Coordenação de Aperfeiçoamento de Pessoal de Ensino Superior (CAPES) pelo financiamento da pesquisa que originou o artigo.

\section{REFERÊNCIAS}

BOOF, Leonardo 1938 - As quatro ecologias: ambiental, política e social, mental e integral / Leonardo Boff. - Rio de Janeiro: Mar de ideias: Animus Anima, 2012.

BRASIL. Ministério da Educação. Secretaria de Educação Básica. Diretrizes curriculares nacionais para a educação infantil / Secretaria de Educação Básica. - Brasília: MEC, SEB, 2010. Disponível em: http://portal.mec.gov.br/dmdocuments/diretrizescurriculares_2012.pdf . Acesso: 05 out. 2020.

BRASIL. Lei de Diretrizes e Bases. Lei 9.394, de 20 de dezembro de 1996. Disponível em: http://portal.mec.gov.br/seed/arquivos/pdf/tvescola/leis/lein9394.pdf Acesso: 05 out. 2020.

BRASIL. Estatuto da Criança e do Adolescente. Disponível em:

http://www.planalto.gov.br/ccivil_03/leis/18069.htm Acesso 05 out. 2020.

BRONFENBRENNER, Urie. Bioecologia do desenvolvimento humano: tornando os seres humanos mais humanos. Artmed. 1. Ed. 2011.

CAPRA, Fritjof. A teia da vida: uma nova compreensão científica dos sistemas vivos/ Fritjof, Capra; tradução Newton Roberval Eichemberg. - São Paulo: Cultrix, 2006.

CARVALHO, Rodrigo Saballa de. Entre as culturas da infância e a rotina escolar: em busca do sentido do tempo na educação infantil. Revista Teias v.16. n.41. 124-141. (abr./jun. - 2015): Infância, Literatura e Educação. Disponível em: https://www.e-

publicacoes.uerj.br/index.php/revistateias/article/view/24517. Acesso: 02 mai. 2019.

CECCONELLO, Alessandra Marques; KOLLER, Sílvia H. Inserção Ecológica na comunidade: uma proposta metodológica para o estudo de famílias em situação de risco. In: KOLLER, Silvia H. (org.). Ecologia do desenvolvimento humano: pesquisa e intervenção no Brasil. São Paulo: Casa do Psicólogo, 2004.

ELIAS, Norbet. Sobre o tempo. EditoraZahar; Edição: 1. 1998.

KAPLAN, Carina Viviana. SARAT, Magda. Infância, tempo e escolarização: aproximações sobre o tema no Brasil e na Argentina. Cad. Cedes, Campinas, v.37, n.102, p.277-294, maio-ago., 2017. Disponível em: http://www.scielo.br/pdf/ccedes/v37n102/1678-7110-ccedes-37-102-00277.pdf Acessado em: 23 de mar. 2018.

MISSIO, Joana; ARPINI, Dorían Mônica. O brincar na vivência de rua de crianças: retratos e narrativas a partir do Desenhos. Estórias. Sociedad e Infancias, 2018. DOI: <SN: 2531-0720 <http://dx.doi.org/10.5209/SOCI.59347>, acesso: 26 abr. 2020.

OLIVEIRA, Cristiane Elvira de Assis. MARQUES, Luciana Pacheco. Tempo e infâncias entrelaçados no cotidiano escolar. Educação Unisinos 15(3):172-180, setembro/dezembro 2011. Disponível em: 
http://revistas.unisinos.br/index.php/educacao/article/viewFile/edu.2011.153.01/537 Acesso: 23 mai. 2018.

PISKE, Eliane Lima; GARCIA, Narjara Mendes; YUNES, Maria Angela Mattar. Conversa(ação) sistêmica na/para/com a Educação Ambiental das Infâncias. Bio-Grafía. Escritos sobre laBiología y su Enseñanza. Edición Extraordinaria, p. 895-905, 2019. Disponível em: https://revistas.pedagogica.edu.co/index.php/bio-grafia/article/view/10988. Acesso: 07 mai. 2020.

PISKE, Eliane Lima; GARCIA, Narjara Mendes; YUNES, Maria Angela Mattar. A educação das crianças: qual é o papel do(a) educador(a) da(s) infância(s). In Sandra Maders (Org.). Conversações Cooperativas em Educação- dialogando com Humberto Maturana. Curitiba/PR: Editora CRV, 2020

PISKE, Eliane Lima; YUNES, Maria Angela Mattar; GARCIA, Narjara Mendes. Ambientes educativos como contextos microssistêmicos para o desenvolvimento humano nas infâncias. Itinerarius Reflectionis, 15(3), 01-22, 2019. DOI: https://doi.org/10.5216/rir.v15i3.58821.

PISKE, Eliane Lima; YUNES, Maria Angela Mattar; BERSCH, Angela Adriane Schmidt, PIETRO, Angela Torma. Práticas educativas nas instituições de Acolhimento sob o olhar das crianças. Rev. Educ. Públ. Cuiabá, v. 27. n. 66. P. 905-923, set/dez. 2018. DOI: http://dx.doi.org/10.29286/rep.v27i66.

PISKE, Eliane Lima. GARIA, Narjara Mendes. MADRUGA, MADRUGA, Elisângela Barbosa. YUNES. Maria Ângela Mattar. compreendendo as infâncias e os jogos eletrônicos na educação: uma experiência do estágio de docência semipresencial no curso de pedagogia. Educação e tecnologias inovação em cenários de transição. 2018. Disponível em:

https://cietenped.ufscar.br/submissao/index.php/2018/article/view/225/244. Acesso: 15 de junh. 2020. PISKE, Eliane Lima. NEUWALD, Mariana Costa. GARCIA, Narjara Mendes. Sustentabilidade ambiental, a ética nas e com as relações humanas e as interações afetivas: tríade necessária as pesquisas em Educação Ambiental. Rev. Eletrônica Mestr. Ambient. Rio Grande, Ed. Especial EDEA, n. 1, p.88-101, 2018. Disponível em: https://periodicos.furg.br/remea/article/view/8565/5503. Acesso: 04 abr. 2018.

TUBENCHLAK, Diana. Arte com bebês. - 1 Ed. - São Paulo, Panda Books, 2020.

\section{EDITORA E GRÁFICA DA FURG}

CAMPUS CARREIROS

CEP 96203900

editora@furg.br 